\title{
INFORMACION SOBRE EL SIDA PARA VIAJEROS
}

\author{
Por Jonathan MANN, M.D. \\ Director del Programa Global sobre SIDA \\ ORGANIZACION MUNDIAL DE LA SALUD
}

Al conocer el crecimiento mundial de la propagación del SIDA, muchas personas que viajan por negocios o por placer se preguntan cómo pueden proteger su salud mientras están fuera de casa. Este artículo del Dr. Jonathan MANN, de la Organización Mundial de la Salud en Ginebra, ha sido proyectado para contestar muchas de esas preguntas y proveer una guía sobre el SIDA a los viajeros del mundo; además de su labor como Jefe del Programa Global sobre el SIDA, el Dr. MANN es doctor en medicina y epidemiólogo.

SIDA y temor no deben ser compañeros de viajes; aunque más de 80.000 casos de la enfermedad han sido informados por unos 130 países, no existe razón para temer viajar si uno se comporta en otros países como en el propio.

Como lo dice nuestro boletín "Información sobre el SIDA para viajeros", usted puede protegerse a sí mismo contra el SIDA en cualquier parte del mundo, en casa o viajando, la inquietud por el SIDA no debe impedir viajar a cualquier parte; evitar el SIDA es prioritario para Ud., así, si usted piensa viajar o ya se encuentra en viaje, tiene aquí algunas preguntas y respuestas básicas sobre el SIDA y los viajeros.

P: Pregunta

R: Respuesta

P. ¿Qué es el SIDA y qué puede ser de interés para los viajeros?

R: El SIDA es una enfermedad causada por un virus que ataca el sistema inmunitario de nuestro organismo y puede llevar a infecciones fatales y algunas formas de cáncer. El SIDA es una realidad en el mundo actual y en todo el mundo; por lo tanto, no interesa dónde Ud. viva o viaje, usted necesita conocer sobre el SIDA y cómo fácilmente protegerse conociendo y respetando algunas simples reglas.

E1 SIDA es transmitido por: relaciones sexuales, transfusión de sangre contaminada o de la madre al niño. En términos prácticos, la generalidad de los viajeros residente de cualquier país, deben estar prevenidos contra tres riesgos: relaciones sexuales con una persona infectada; una transfusión sanguínea si la sangre no ha sido investigada, por la posible presencia del virus del SIDA; agujas contaminadas, jeringas u otros elementos que cortan la piel. El SIDA NO se transmite por un contacto casual no sexual o actividades rutinarias como sentarse cerca de alguien en un avión o tren, omnibus, automóvil, bote o taxi; y usted no debe preocuparse por adquirir el SIDA a través de tazas, vasos, platos, baños o a través del agua, el aire, los contactos no sexuales o abrazos; tos o estornudos; tampoco se difunde a través de insectos o piletas de natación.

P. Si las relaciones sexuales son la más importante forma de difusión del SIDA, ¿qué puedo hacer para evitarlo?

R. Puesto que el SIDA puede ser contagiado por una persona infectada a su pareja sexual (hombre a mujer, mujer a hombre, hombre a hombre), la mejor manera es la abstinencia sexual durante los viajes con parejas diferentes a su compañero o compañera habitual o las relaciones con una pareja fiel y no infectada. Si usted decide tener relaciones se- 
xuales con alguien que puede estar infectado, debe usar preservativo (Condón), en cada oportunidad, desde el comienzo hasta el final del acto sexual. No tenga relaciones sexuales con prostitutas o conocidos casuales, aún en países que se dicen libres del SIDA, usted no puede saber por las apariencias cuando alguién está infectado.

P. ¿Qué hacer si alguien que yo conozco viaja con el propósito de lo que algunos llaman "turismo sexual”. Qué puedo decirle?

R. Es particularmente importante que esas personas comprendan que el. SIDA es un agente mundial, que no existen "zonas seguras" para el sexo; sin embargo, los viajes pueden llevar a una sensación de liberación de los usuales cuidados y responsabilidades, y al "sindrome del crucero romántico". Los viajes pueden dar la sensación de que ciertas cosas se tornan permisibles, incluyendo los contactos sexuales, que no son habituales en la vida del hogar; por lo tanto es muy importante que la gente que viaja sea consciente de estos hechos y no olvide que las precauciones tomadas en su casa siguen siendo importantes y deben ser continuadas.

\section{P. ¿Qué países requieren análisis o certifica-} dos para el SIDA?

R. De acuerdo a nuestro conocimiento, sólo un país, IRAK exige análisis a los turistas y otros visitantes por lapsos breves. Algunos países exigen análisis para el SIDA a los estudiantes, trabajadores y otras personas que piensen permanecer por períodos mayores de un mes; sin embargo, la mayoría de los países no exigen ninguno de dichos análisis. viaje?

\section{P. ¿Qué debemos hacer antes de iniciar un}

R. Visite su Centro de Salud de costumbre (o médico) y descríbale su itinerario; de esta manera Ud. podrá beneficiarse con todas las protecciones sanitarias apropiadas. Estas podrán incluir protección contra la malaria, ciertas inmunizaciones y precauciones generales, así como información sobre el SIDA. Si usted se enfermara a su regreso, informe a su médico dónde ha estado; ésto puede dar vital información sobre cuál puede haber sido el daño y puede ser lo que salve su vida.

P. ¿Qué se puede decir sobre las transfusiones de sangre en algunas partes del mundo? ¿Son seguras?

R. Primero que todo, la gente puede hacer mucho para evitar el riesgo de necesitar una transfusión durante un viaje, muchos daños pueden evitarse si se los previene. Tomemos por ejemplo los accidentes automovilísticos: póngase cinturones de seguridad, no tome alcohol al conducir, conduzca con cuidado, aprenda cómo se dice "despacio" y "pare" en el idioma local. Pero si usted necesita una transfusión de sangre, trate de asegurarse que se utilice sangre estudiada; en la actualidad este estudio se realiza en forma rutinaria en muchos países. Desde que más y más países en todo el mundo, analizan en la actualidad la sangre para investigar el virus del SIDA, las transfusiones de sangre se verán cada vez más protegidas contra la contaminación por este virus. viaje?

P. ¿Puedo yo recibir mi propia sangre en un

R. Esto es virtualmente imposible y sería peligroso, la sangre debe ser acondicionada y almacenada en forma apropiada (Bancos de Sangre); debe ser suministrada en forma correcta. Recibir vuestra propia sangre es hoy impracticable y tal vez dañoso.

P. ¿Qué hacer si necesito un medicamento inyectable?

R. De una manera general, evite las inyecciones salvo que sean absolutamente necesarias. Si usted debe recibir una inyección, asegúrese que aguja $\mathrm{y}$ jeringa sean nuevas y provengan directamente de un paquete estéril cerrado (desechables). Si ésto no fuere posible y aguja y jeringa han sido ya usadas anteriormente, asegúrese que hayan sido lavadas y .adecuadamente esterilizadas en agua hirviente por un período de 20 minutos. Salvo que usted tenga una prescripción o receta médica, no lleve las agujas consigo; finalmente, si usted utiliza drogas de cualquier tipo, nunca utilice los elementos de cualquier otra persona para aplicárselas.

P. ¿Puede la acupuntura o la perforación del lóbulo de la oreja ser peligroso?

R. Sí, si las agujas u otros instrumentos no han sido adecuadamente lavados y esterilizados. La adecuada esterilización de las agujas de acupuntura, herramientas de odontología, o cualquier elemento que perfore la piel, elimina el riesgo de perforación por SIDA.

P. ¿Qué ocurre cuando alguien está infectado por SIDA? ¿Puede viajar?

R. Las personas enfermas con SIDA o cualquier otra enfermedad mayor pueden no ser acep- 
tadas en un país extranjero y negárseles la entrada, por tal motivo es muy importante informarse sobre las ordenanzas antes de viajar para evitar problemas. Si usted se encuentra actualmente infectado con el virus del SIDA, aun cuando se encuentre sano consulte a su agente sanitario (médico) para su orientación mucho antes de iniciar su pretendido viaje.

P. ¿Cuáles son sus consejos finales?

R. El SIDA no debe causarle a usted más temor cuando viaje al exterior que cuando usted va a una ciudad vecina en su propio país. El conocimiento previo de los lugares a donde usted se dirige, puede hacer a su viaje más interesante y agradable; el conocimiento sobre la prevención del SIDA es la clave para evitar su infección. No tome riesgos que puedan enviar el SID $\Lambda$ a su casa con usted; el mayor riesgo lo correrá si mantiene relaciones sexuales con parejas ocasionales; si este consejo puede parecerle muy estricto, recuerde esto: en ausencia de una vacuna o tratamiento eficaz para el SIDA, su prevención es la única protección.

\section{CURSO DE ACTUALIZACION EN GINECOLOGIA Y OBSTETRICIA}

Bogotá, Septiembre 8 - 9 de 1988

\section{SALON FELIX RESTREPO}

DE LA UNIVERSIDAD JAVERIANA

\section{PROGRAMA}

Septiembre 8 - Mañana

8.00 Inauguración

8.30 ¿Tiene valor la Ecografía en Ginecología? Dres.: E. Acosta, P. Duque, M. Cruz COORDINADOR: Dr. Jairo de la Cruz Segura

9.30 Procedimientos Terapéuticos Intrauterinos Dres:: E. Acosta, L.C. Jiménez, E. Ortiz COORDINADOR: Dr. Eduardo Acosta Lleras

10.30 Descanso

11.00 Antibioterapia en Ginecobstetricia Dres.: A. Lozano, J. Afanador, F. Isaza COORDINADOR: Dr. Germán Sabogal

12.00 Almuerzo

Tarde

2.00 Hemorragia Uterina Anormal Dres.: J. Urdinola, W. Onatra, B. Moreno COORDINADOR: Dr. Jaime Ferro Camargo

3.00 Vigilancia Fetal Dres.: J.L. Duque, G. Páez, A. Correa COORDINADOR: Dr. Jairo de la Cruz Segura

\subsection{Café}

4.30 Patología Benigna del Seno Dres.: F. Perry, H. Sánchez, F. Pardo COORDINADOR: Dr. Francisco Revollo Pardo

Septiembre 9 - Mañana

8.30 Cáncer de Ovario Dres.: M. González, G. Martínez, L.F. Botero COORDINADOR: Dr. Hugo Quijano
9.30 Incontinencia Urinaria de Esfuerzo Dres.: A. Lomanto, H. Redondo, J. Gómez COORDINADOR: Dr. Jaime Díaz

10.30 Café

11.00 Implicaciones Médico-legales y Eticas en Ginecobstetricia Dres.: F. Sánchez, A. Tamavo (Abogado). COORDINADOR: Dr. Germán Uriza Gutiérrez

12.00 Almuerzo

Tarde

2.00 Endometriosis: Manejo Dres.: F. del Corral, L.E. Pérez, J. Botero Uribe COORDINADOR: Dr. Jaime Ferro Camargo

3.00 Colposcopia y lesiones Premalignas y Virales del Cervix Dres.: A. Angulo, A. Pachón, H. Ortiz COORDINADOR: Dr. José María Fuentes

\subsection{Café}

4.30 Climaterio: Manejo Dres.: M. Riaño, R. Jaramillo, A. Jácome COORDINADOR: Dr. Víctor Rodríguez Romero

\section{VALOR INSCRIPCIONES}

$\begin{array}{lrr}\text { Médicos No Miembros SCOG } & \$ & 10.000 .00 \\ \text { Médicos Miembros SCOG } & \$ & 8.000 .00 \\ \begin{array}{l}\text { Estudiantes Internos y } \\ \text { Residentes }\end{array} & & \\ & \$ & 6.000 .00\end{array}$

INFORMES: Carrera 23 No. 39-82 Teléfono 2681485 Bogotá, D. E. - Colombia 